\title{
Population decline of the cape petrel (Daption capense) on King George Island, South Shetland Islands, Antarctica
}

\author{
Christina Braun $^{1}\left[\right.$ ] Jan Esefeld ${ }^{1} \cdot$ Larisa Savelieva $^{2} \cdot$ Hans-Ulrich Peter $^{1}$
}

Received: 15 July 2020 / Revised: 14 July 2021 / Accepted: 16 July 2021 / Published online: 26 July 2021

(c) The Author(s) 2021

\begin{abstract}
The Antarctic and the surrounding Southern Ocean are currently subject to rapid environmental changes and increasing anthropogenic impacts. Seabird populations often reflect those changes and so act as indicators of environmental variability. Their population trends may provide information on a variety of environmental parameters on the scale of years or decades. We therefore provide long-term data on the cape petrel (Daption capense) population from a long-term monitoring program on Fildes Peninsula, South Shetland Islands, Maritime Antarctic, an area of considerable human activity. Our data, covering a period of 36 years, indicate some variability, but no clear trend in the number of breeding pairs between the breeding seasons 1985 and 2006. However, beginning in the 2008 season, the population decreased significantly and reached a minimum in the 2020 season. The mean annual decrease between 2008 and 2020 was $10.6 \%$. We discuss possible causes of this strong negative population trend. Anthropogenic disturbance only affects a few breeding sites in the area and is therefore unable, on its own, to explain the consistent population decline at all the breeding sites studied. We think it more likely that reduced food availability was the main cause of the drastic decline in the cape petrel population.
\end{abstract}

Keywords Daption capense $\cdot$ Environmental changes $\cdot$ Food availability $\cdot$ Fulmarine seabird $\cdot$ Indicator species $\cdot$ South Shetland Islands

\section{Introduction}

Seabirds are valuable indicators of the health of the ecosystem of which they are part (Thibault et al. 2019; Velarde et al. 2019). In particular, specialist predators provide crucial information about their prey stocks (Montevecchi 1993; Furness and Camphuysen 1997; Piatt et al. 2007). This is particularly important because of the current rapid environmental changes on the Antarctic Peninsula and the increasing fishing activities in the surrounding Southern Ocean (e.g. Croxall et al. 2002; Constable et al. 2014; Turner et al. 2014). Because of this importance of predatory sea bird numbers, the Commission for the Conservation of Antarctic Marine Living Resource (CCAMLR) initiated its

Christina Braun

Chr.Braun@uni-jena.de

$1 \quad$ Polar \& Bird Ecology Group, Institute of Ecology and Evolution, Friedrich Schiller University Jena, Dornburger Str. 159, 07743 Jena, Germany

2 Institute of Earth Sciences, St. Petersburg State University, Universitetskaya 7/9, St. Petersburg 199034, Russia
Ecosystem Monitoring Program (CEMP) in order to record significant changes in critical components of the ecosystem (CCAMLR 2014). This programme monitors, with a set of standard methods species, selected as being likely to be affected by changes in the availability of commercially harvested species (currently krill and fish) (CCAMLR 2014). One of these CEMP indicator species is the cape petrel or Pintado petrel (Daption capense). The main breeding areas of this species are along the Antarctic Peninsula, South Georgia and various other Antarctic and Subantarctic islands (Marchant and Higgins 1990; Schrimpf et al. 2020). Like most other Procellariform birds, cape petrels are highly philopatric (Weidinger 1996a). The global population of the species is currently estimated at over 2 million individuals (Brooke 2004, cited in BirdLife International 2020) and, due to the lack of evidence to the contrary, it is considered as stable (IUCN-Status "least concern", BirdLife International 2020). Despite several studies on particular aspects in the breeding and foraging ecology of the species (e.g. Arnould and Whitehead 1991; Weidinger 1996a, 1997, 1998b; Coria et al. 1997) there are few surveys of their abundance (e.g. Coria et al. 1995, 1996; Woehler and Croxall 1997; Bó and 
Copello 2000; Lumpe and Weidinger 2000; Soave et al. 2000b; Sierakowski et al. 2017; Petry et al. 2018), but these mostly do not allow any assessment of population trends. This is mainly due to cape petrel breeding habits as the birds nest on rock ledges and cliffs along the coastline and this usually hinders accurate counting. Hence, there is a lack of regional or global population assessments. To remedy this lack we assembled long-term data on a local breeding population of cape petrels in the Maritime Antarctic. The importance of the investigations lies in the listing of the species as a dependent or indicator species within the CCAMLR Ecosystem Monitoring Program in order to detect and record significant changes in critical components of the ecosystem (CCAMLR 2014). The study area is located within the CCAMLR Statistical Area No. 48.1.

\section{Materials and methods}

The study was conducted on the Fildes Peninsula and adjacent Ardley Island (hereafter Fildes Peninsula, $62^{\circ} 10^{\prime} \mathrm{S}$, $59^{\circ} 0^{\prime} \mathrm{W}$ ) southwest King George Island, South Shetland
Islands, Maritime Antarctic (Fig. 1). The study area covers $\sim 35 \mathrm{~km}^{2}$ and is one of the largest ice-free areas of the Antarctic Peninsula region. It hosts thirteen breeding bird species (Braun et al. 2012). Two Antarctic Specially Protected Areas have been designated in the study area due to its relatively high biodiversity (ASPA No. 150 Ardley Island) and rich fossil outcrops (ASPA No. 125). However, the area contains many Antarctic stations and, consequently, is affected by a variety of human activities including research, logistics, tourism and educational programs. We extracted data on the distribution and intensity of human impact from published sources (Peter et al. 2008, 2013) and added data from our own observations for subsequent years.

On the Fildes Peninsula, cape petrel breeding sites are located mainly on rock ledges and steep cliffs along the coastline. Due to the local topography, most of the suitable breeding grounds are on the western coast (Fig. 1). The cape petrel breeding sites are barely accessible but well visible from the shore below the cliffs or from the top of opposite cliffs. We were thus able to systematically count the number of apparently occupied nests (AON; see Creuwels et al. 2005) within a few days during the incubation period

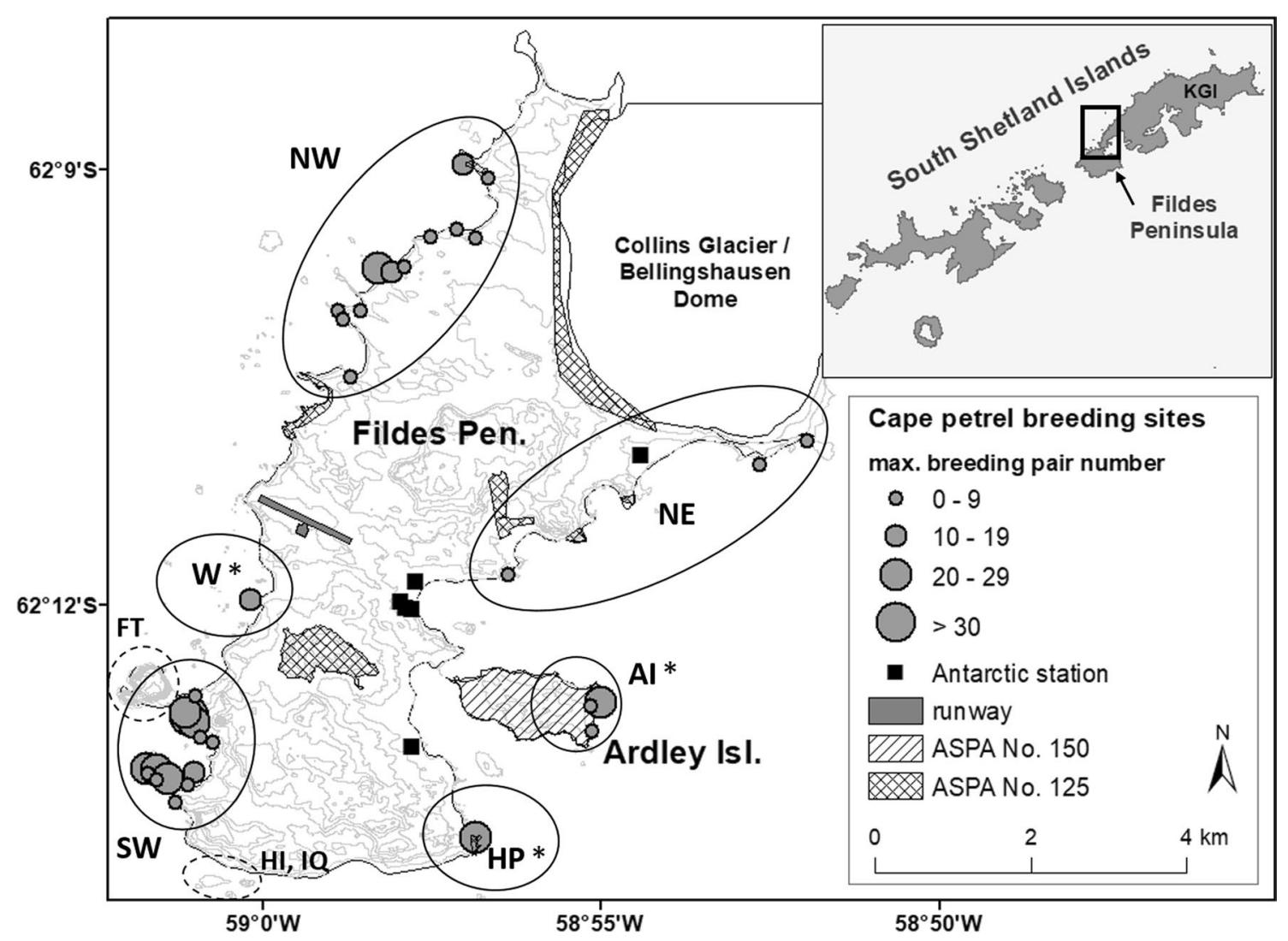

Fig. 1 Distribution of cape petrel (Daption capense) breeding sites on the Fildes Peninsula and Ardley Island in the southwest of King George Island, South Shetland Islands, Antarctica. The size of the filled circles indicate the maximum number of breeding pairs from
2004 to 2020 . Regional breeding clusters are represented by ovals. Clusters affected by human activity are marked by asterisks. Dashed ovals indicate colonies of which only population estimates are available 
(census between 25 November and 23 December, median: 16 December). We used detailed maps of all known breeding sites and examined them, and other likely areas, with binoculars. Because mean colony attendance remains almost constant in the incubation period, we used the number of AON as a proxy for the breeding pair number even though using this proxy results in a high probability of including failed breeders or non-breeders (Weidinger 1996b; Creuwels et al. 2005). We counted all breeding pairs from a distance, even when nests were easily accessible, so as to avoid our disturbing the birds. It is unlikely that we overlooked many breeding pairs because the complete coastline was regularly monitored during the austral summer. Data were either extracted from published and unpublished reports of the seasons $1984 / 85$ to $1986 / 87,1989 / 90,2000 / 01$ and $2007 / 08$ (Table 1) or obtained from 2003/04 to 2005/06 and 2008/09 to 2019/20 (hereafter named as season 2009, 2020, etc.) from our own GPS-based studies. Because it was difficult to allocate data from the historical reports to specific locations, we grouped the data into clusters (NW-Northwest, W- West, SW-Southwest, NE-Northeast, AI-Ardley Island, HP-Halfthree Point, Fig. 1). Data on breeding pair numbers of breeding sites on islands in the adjacent Fildes Strait (Heidelberginsel-HI, Isla Quintana-IQ) as well as the Flat Top (FT) breeding site were mostly obtained by estimation or by census at a distance. No data on reproductive performance were collected in the study area. The map was created using SigmaPlot 14.0 and the graph using ArcGIS 10.5. The mean annual change rate was calculated as: annual change $(\%)=\left(\left(\mathrm{P}^{(\mathrm{t}+1)} / \mathrm{P}^{(\mathrm{t})}\right)-1\right) * 100$ (Carlini et al. 2009) where $P$ : population size, $t$ : year.

\section{Results}

Since the beginning of seabird monitoring, we recorded 37 breeding sites of cape petrels on the Fildes Peninsula (Fig. 1). The total number of breeding pairs at the different

Table 1 Breeding pair numbers (bp) of cape petrel (Daption capense) breeding clusters in the Fildes Region

\begin{tabular}{|c|c|c|c|c|c|c|c|c|c|}
\hline Zone/Season & NW & $\mathrm{W}^{*}$ & SW & $\mathrm{HP}^{*}$ & $\mathrm{AI}^{*}$ & NE & Total bp & Census date & Data source \\
\hline 1980 & - & - & - & - & 8 & - & - & December & R. Bannasch, K. Odening ${ }^{a}$ \\
\hline 1981 & - & - & - & - & 3 & - & - & December & Bannasch et al. 1984 \\
\hline 1982 & - & - & - & - & 5 & - & - & 06.12 .1981 & Bannasch et al. 1984 \\
\hline 1984 & - & - & - & - & 3 & - & - & 25.11 .1983 & H. Lorenz $z^{\mathrm{a}}$ \\
\hline 1985 & 15 & 0 & 248 & 6 & 9 & 6 & 284 & 13. -17.12 .1984 & Peter et al. 1988 \\
\hline 1986 & 27 & 0 & 291 & 12 & 8 & 0 & 338 & December & M. Rauschert ${ }^{\mathrm{a}}$ \\
\hline 1987 & 15 & 0 & 220 & 6 & 3 & 0 & 254 & 09.12 .1986 & R. Mönke, A. Bick ${ }^{\mathrm{a}}$ \\
\hline 1989 & - & - & - & - & 7 & - & - & 22.11 .1988 & U. Lange, J. Naumann ${ }^{\mathrm{a}}$ \\
\hline 1990 & 6 & 0 & 230 & 10 & 7 & 0 & 253 & $30.11 .-02.12 .1989$ & J. Erfurt, H. Grimm ${ }^{\mathrm{a}}$ \\
\hline 1996 & & - & - & - & 30 & - & - & $23.12 .1995-20.01 .1996$ & Soave et al. 2000b \\
\hline 2001 & 35 & 0 & 104 & 13 & 15 & 0 & 167 & $30.12 .2000-11.01 .2001$ & Own data \\
\hline 2004 & 22 & 10 & 154 & 26 & 25 & 5 & 242 & 06.01.-17.01.2004 & Own data \\
\hline 2005 & 42 & 8 & 164 & 8 & 29 & 8 & 259 & 20.12 .2004 & Own data \\
\hline 2006 & 45 & 8 & 234 & 10 & 24 & 8 & 329 & 18.12 .2005 & Own data \\
\hline 2008 & 20 & 11 & 145 & 3 & - & 0 & 179 & 06.01.-17.01.2008 & Own data \\
\hline 2009 & 19 & 6 & 142 & 1 & 18 & 4 & 190 & 15.-18.12.2008 & Own data \\
\hline 2010 & 11 & 0 & 129 & 1 & 9 & 2 & 152 & 11. -23.12 .2009 & Own data \\
\hline 2011 & 5 & 6 & 137 & 5 & 8 & 2 & 163 & 17. -20.12 .2010 & Own data \\
\hline 2012 & 18 & 4 & 77 & 2 & 2 & 1 & 104 & 22.-23.12.2011 & Own data \\
\hline 2013 & 6 & 3 & 46 & 0 & 7 & 0 & 62 & 18.-19.12.2012 & Own data \\
\hline 2014 & 1 & 2 & 18 & 0 & 1 & 0 & 22 & 13. -15.12 .2013 & Own data \\
\hline 2015 & 2 & 1 & 12 & 0 & 0 & 0 & 15 & 12.-13.12.2014 & Own data \\
\hline 2016 & 0 & 5 & 4 & 0 & 0 & 0 & 9 & 11.-20.12.2015 & Own data \\
\hline 2017 & 2 & 1 & 30 & 0 & 1 & 0 & 34 & 15.-19.12.2016 & Own data \\
\hline 2018 & 0 & 2 & 7 & 0 & 2 & 0 & 11 & 16.-17.12.2017 & Own data \\
\hline 2019 & 0 & 0 & 8 & 0 & 0 & 0 & 8 & 12. -17.12 .2018 & Own data \\
\hline 2020 & 0 & 1 & 0 & 0 & 0 & 0 & 1 & 08.-9.12.2019 & Own data \\
\hline
\end{tabular}

*Area affected by human activities

${ }^{\mathrm{a}}$ Unpublished expedition report 
sites mapped between 2004 and 2020 ranged between one and 83 breeding pairs. In total, we assembled data from up to 26 breeding seasons. The number of breeding pairs of cape petrels on the Fildes Peninsula and Ardley Island showed some degree of variability between 1985 and 2006 (Fig. 2). It ranged between 203 in the 2004 season and 338 in the 1986 season (Table 1). However, beginning in the 2008 season, the population decreased drastically with a mean annual change rate of $-10.6 \%$. The number reached a minimum in the 2020 season (Fig. 2; Table 1), when only one breeding pair was recorded. Considerable human impact was only recorded in the area of three smaller breeding clusters (W, HP and AI, Fig. 1). These clusters are often frequented by scientists and station personnel (Peter et al. 2008; Braun et al. 2012), even though the breeding clusters HP and AI are located within an ASPA (Fig. 1), where all unauthorized access is prohibited. All other breeding sites (NE, SW, NE) are located in more remote areas and are on rock faces or steep cliffs and are therefore hardly ever affected by direct human activity. Despite the temporary intense sea and air traffic in the study area during the austral summer, there was no increased bird activity in the petrel colonies during boat and aircraft operations. The waters off the west coast of the Fildes Peninsula are not navigable and are therefore not affected by boat traffic. Aircraft operations mainly occur above the central part of the Fildes Peninsula in an east-west axis towards the runway (Fig. 1). No spatial differences in the cape petrel population decline were detected within the study area, as the breeding pair numbers at all breeding clusters decreased in the same way (Table 1, additional graphs are given in Online Resource 1). The declining trend is supported by data from breeding sites adjacent to the Fildes

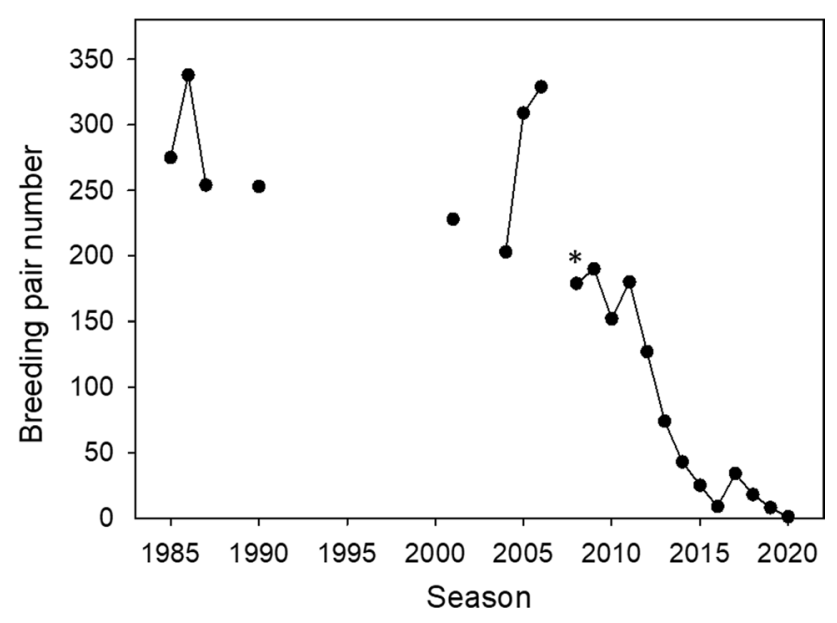

Fig. 2 Number of breeding pairs of cape petrel (Daption capense) on the Fildes Peninsula and Ardley Island in the southwest of King George Island, South Shetland Islands, Antarctica. Year refers to time of chick fledging. Incomplete data are marked by asterisk. Data sources are listed in Table 1
Peninsula. These, however, are estimations (Online Resource 2).

\section{Discussion}

The number of breeding pairs of cape petrels on the Fildes Peninsula and Ardley Island recently experienced a dramatic decline. Numbers went from several hundred breeding pairs to a virtually none. We were unable to investigate the reason for this collapse within the framework of the seabird monitoring program. Nevertheless, we posit a number of possible explanations. One such explanation is human activity. This is particularly prevalent on the Fildes Peninsula because of its several Antarctic research stations. Direct anthropogenic disturbance reduces the local breeding populations of several seabird species. Those affected include the southern giant petrel (Macronectes giganteus), brown skua (Stercorarius antarcticus lonnbergi), south polar skua (Stercorarius maccormicki), kelp gull (Larus dominicanus), Antarctic tern (Sterna vittata), Wilson's storm petrel (Oceanites oceanicus) and black-bellied storm petrel, (Fregetta tropica) (Chupin 1997; Peter et al. 2008, 2013; Braun et al. 2012). However, this explanation cannot be the cause of the collapse in cape petrel numbers because the collapse affected all breeding sites similarly. The decline was not greater in sites where there was more disturbance pressure. Therefore, anthropogenic disturbance alone is unable to explain the significant decline in breeding pair numbers on the Fildes Peninsula.

Predation by skuas cause substantial breeding failure in cape petrels (Weidinger 1998a). This is despite cape petrels usually nesting on cliffs and rock ledges and so protecting their offspring from predation.

Skuas are generalist predators with a variety of foraging strategies (Carneiro et al. 2015), but some populations specialize on one or few prey species (Mougeot et al. 1998; Reinhardt et al. 2000; Pacoureau et al. 2019). Some of the brown skua breeding pairs on the Fildes Peninsula and Ardley Island forage to a large extent on seabirds other than penguins, including storm petrels or cape petrels (Peter et al. 1988). The high brown skua density in the study area therefore results in high predation on local seabird populations. This was confirmed by Weidinger (1998a) in several nearby cape petrel colonies. However, the brown skua population in the study area was stable over the years of cape petrel collapse (Krietsch et al. 2016) and thus predation alone is unable to explain the sudden decline in one prey species when others are unaffected. In addition, because skuas are generalist feeders, they are easily able to switch to other prey and alternative prey are abundant in the area as several seabird species breed there (Braun et al. 2017). Therefore, we assume severe predation contributes little to the drastic decline of the local cape petrel population, although it was 
not possible to quantify its impact in this study. We therefore suspect that a more likely cause of the sharp population decline is a change in environmental conditions, possibly a lack of food or bad weather conditions. Climatic conditions are certainly able to influence the number of breeding pairs in seabirds (e.g. Trathan et al. 2007). However, since the 2008 season, when the petrel collapse seems to have begun, there have been both cool and warm summers. There has not been a steady change in summer temperatures in either direction that parallels the collapse of the petrel population. Rainfall likewise has neither consistently increased nor decreased since 2008. In any case, unlike ground-nesting birds, cape petrels nest on cliffs and rock ledges and so are protected from precipitation to a degree. We believe, therefore, that local climatic conditions played a minor role in the cape petrel population decline. It is possible, however, that climate during the non-breeding season (winter and spring) or the previous breeding season affects the survival of offspring and adults and so also the number of breeding pairs in subsequent seasons (Petry et al. 2016). Unfortunately, we were unable to test this contention because we have no data on mortality outside the breeding season.

The cape petrel is an opportunistic surface feeder (Soave et al. 2000a). Its diet consists mainly of Antarctic silverfish (Pleuragramma antarctica), myctophids, Antarctic krill (Euphausia superba) and, in a smaller proportion, of amphipods (Arnould and Whitehead 1991; Coria et al. 1997; Casaux et al. 1998). The species composition of the diet, and the proportions of these species, differ considerably between seasons and breeding areas and seem, generally, to reflect prey availability (Coria et al. 1996; Casaux et al. 1998; Soave et al. 2000a). The current decline in the cape petrel population on the Fildes Peninsula is not matched by declines in populations of other seabird populations in the area, namely Adélie penguin (Pygoscelis adeliae), chinstrap penguin (Pygoscelis antarcticus), gentoo penguin (Pygoscelis papua), southern giant petrel, and kelp gull (Braun et al. 2020). However, the petrel decline does correspond with major fluctuations in the number of south polar skua breeding pairs in the area and repeated breeding failures of this species (Krietsch et al. 2016). Repeated breeding failures in south polar skuas indicate a drastic shortage in prey availability (Krietsch et al. 2016). South polar skuas share the surface feeding behaviour of cape petrels and their diets considerably overlap. Both species use the same food source in the study area (Creet et al. 1994; Casaux et al. 1998; Reinhardt et al. 2000). Therefore, it is likely that local prey availability has varied considerably over recent years with, in consequence, major effects on the two predator species (Krietsch et al. 2016). We therefore conclude that reduced food availability is the main cause of the cape petrel collapse. However, to substantiate this conclusion, more information is required on the foraging areas of cape petrels and on krill and fish stocks in the foraging area. It is also necessary to determine the impact on the birds of the fishing industry and of environmental change as both of these are able to reduced food availability (Bertrand et al. 2012; Trathan et al. 2015; Hinke et al. 2017).

To what extent the cape petrel population decline on the Fildes Peninsula is reflected in other breeding areas is not clear because appropriate population data are lacking. The little information that does exist is inconsistent and mostly not based on current data (Woehler and Croxall 1997). Thus, Sierakowski et al. (2017) reported a substantial increase of breeding cape petrels between 1979 and 1997 in Admiralty Bay, King George Island. The same was found for Harmony Point, Nelson Island, between 1964 and 1989 or 1995 (Silva et al. 1998). In contrast, Petry et al. (2016) reported both an increase of breeding pairs as well as the disappearance of some smaller breeding colonies between 1979 and 2011 in Admiralty Bay in the period. However, Petry et al. (2018) reported a considerable decline from approximately 1500 breeding pairs in 1988 to approximately 600 breeding pairs in 2014 for Elephant Island. Published data on breeding success are even scarcer. Thus, the results presented here are among the first reports of a declining local cape petrel populations. In consequence, more population data on this species are needed for an inter-regional comparison of the population trend in the Antarctic.

Supplementary Information The online version contains supplementary material available at https://doi.org/10.1007/s00300-021-02914-4.

Acknowledgements We thank for their field work the participants of the German expeditions made during the 1980s as well as the current and former members of the Polar \& Bird Ecology Group. Since 2003 the study was part of various monitoring projects commissioned by the German Environment Agency (FKZ 20313 124, FKZ 370891 102, FKZ 371287 100, FKZ 3715192130 and FKZ 371818100 0). We also thank the reviewers K. Weidinger, J. C. S. Creuwels and Gisele P. M. Dantas for their helpful comments and suggestions on improving the manuscript. The manuscript was edited during revision by Dr A.J. Davis, English Experience Language Services, Göttingen, Germany.

Author contributions CB was largely responsible for the conception or design of the work, the acquisition, compilation, analysis, and interpretation of data and wrote and revised the manuscript. JE contributed to the data collection and critically revised the manuscript. LS contributed to the manuscript. HUP made substantial contributions to the conception or design of the work, contributed to the data collection and critically revised the manuscript. All authors read and approved the manuscript.

Funding Open Access funding enabled and organized by Projekt DEAL. Seabird monitoring in the seasons 2003/04 to 2005/06 and 2009/10 to 2019/20 was commissioned by the German Environment Agency (FKZ 20313 124, FKZ 370891 102, FKZ 371287 100, FKZ 3715192130 and FKZ 371818100 0).

Data availability The data are available on reasonable request. 
Code availability Not applicable.

\section{Declarations}

Conflict of interest There are no conflicts of interests.

Ethical approval Not applicable.

Consent to participate All co-authors commented on previous versions of the manuscript.

Consent for publication All authors read and approved the final manuscript.

Open Access This article is licensed under a Creative Commons Attribution 4.0 International License, which permits use, sharing, adaptation, distribution and reproduction in any medium or format, as long as you give appropriate credit to the original author(s) and the source, provide a link to the Creative Commons licence, and indicate if changes were made. The images or other third party material in this article are included in the article's Creative Commons licence, unless indicated otherwise in a credit line to the material. If material is not included in the article's Creative Commons licence and your intended use is not permitted by statutory regulation or exceeds the permitted use, you will need to obtain permission directly from the copyright holder. To view a copy of this licence, visit http://creativecommons.org/licenses/by/4.0/.

\section{References}

Arnould JPY, Whitehead MD (1991) The diet of Antarctic petrels, Cape petrels and southern fulmar rearing chicks in Prydz Bay. Antarct Sci 3:19-27

Bannasch R, Feiler K, Rauschert M (1984) Fortsetzung der biologischen Untersuchungen im Gebiet der sowjetischen Antarktisstation Bellingshausen. In: Bannasch R, Feiler K, Rauschert M (eds) Geodätische und geophysikalische Veröffentlichungen Reihe. Nationalkomitee für Geodasie und Geophysik bei der Akademie der Wissenschaften der DDR, 1984, Berlin, pp 1-63

Bertrand S, Joo R, Smet CA, Tremblay Y, Barbraud C, Weimerskirch $\mathrm{H}$ (2012) Local depletion by a fishery can affect seabird foraging. J Appl Ecol 49:1168-1177

BirdLife International (2020) Species factsheet: Daption capense. http://datazone.birdlife.org/species/factsheet/cape-petrel-dapti on-capense. Accessed 26 March 2020

Bó MS, Copello S (2000) Distribution and abundance of breeding birds at Deception Island, South Shetland Islands, Antarctica, February to April 2000. Mar Ornithol 29:39-42

Braun C, Mustafa O, Nordt A, Pfeiffer S, Peter H-U (2012) Environmental monitoring and management proposals for the Fildes region (King George Island, Antarctica). Polar Res 31:18206

Braun C, Esefeld J, Peter H-U (2017) Monitoring the consequences of local climate change on the natural resources of the ice-free regions of Maxwell Bay (King George Island, Antarctic). On behalf of the German Environment Agency, Texte 26/2017, Dessau-Rosslau, https://www.umweltbundesamt.de/publikatio nen/monitoring-the-consequences-of-local-climate-change

Braun C, Hertel F, Ritter R, Peter H-U (2020) Long-term monitoring reveals divergent population trends for six seabird species in the Maritime Antarctic. Paper presented at the Presented at: SCAR 2020 Online, https://az659834.vo.msecnd.net/eventsairs easiaprod/production-leishman-public/6de89e8aab014771a95b $424 b 4 f 32965 a$
Brooke M (2004) Albatrosses and Petrels across the World. Bird Families of the World. Oxford University Press, Oxford

Carlini AR, Coria NR, Santos MM, Negrete J, Juáres MA, Daneri GA (2009) Responses of Pygoscelis adeliae and P. papua populations to environmental changes at Isla 25 de Mayo (King George Island). Polar Biol 32:1427-1433

Carneiro APB, Manica A, Trivelpiece WZ, Phillips RA (2015) Flexibility in foraging strategies of Brown Skuas in response to local and seasonal dietary constraints. J Ornithol 156:625-633

Casaux R, Soave G, Coria N (1998) Laternfish (Myctophidae) in the diet of the Cape petrel Daption capense at the South Shetland and South Orkney Islands, Antarctica. Polar Biol 20:364-366

CCAMLR (2014) Standard Methods of the CCAMLR Ecosystem Monitoring Program. Hobart, Tasmania

Chupin I (1997) Human impact and breeding success in Southern Giant Petrel Macronectes giganteus on King George Island (South Shetland Islands). Korean J Polar Res 8:113-116

Constable AJ, Melbourne-Thomas J, Corney SP et al (2014) Climate change and Southern Ocean ecosystems I: how changes in physical habitats directly affect marine biota. Global Change Biol 20:3004-3025

Coria NR, Favero M, Silva P, Casaux R (1995) Breeding birds at Duthoit Point, Nelson Island, South Shetland Islands, Antarctica. Mar Ornithol 23:61-64

Coria NR, Blendinger PG, Montalti D (1996) The breeding birds of Cape Geddes, Laurie Island, South Orkney Islands, Antarctica. Mar Ornithol 24:43-44

Coria NR, Soave GE, Montalti D (1997) Diet of Cape petrel Daption capense during the post-hatching period at Laurie Island, South Orkney Islands, Antarctica. Polar Biol 18:236-239

Creet S, van Franeker JA, van Spanje TM, Wolff WJ (1994) Diet of the Pintado Petrel Daption capense at King George Island, Antarctica, 1990-91. Mar Ornithol 22:221-229

Creuwels JCS, Stark JS, Woehler EJ, van Franeker JA, Ribic CA (2005) Monitoring of a Southern Giant Petrel Macronectes giganteus Population on the Frazier Islands, Wilkes Land, Antarctica. Polar Biol 28:483-493

Croxall JP, Trathan PN, Murphy EJ (2002) Environmental Change and Antarctic Seabird Populations. Science 297:1510-1514

Furness RW, Camphuysen KCJ (1997) Seabirds as monitors of the marine environment. ICES J Mar Sci 54:726-737

Hinke JT, Cossio AM, Goebel ME, Reiss CS, Trivelpiece WZ, Watters GM (2017) Identifying risk: concurrent overlap of the Antarctic krill fishery with krill-dependent predators in the Scotia Sea. PLoS ONE 12:e0170132

Krietsch J, Esefeld J, Braun C, Lisovski S, Peter H-U (2016) Long-term dataset reveals declines in breeding success and high fluctuations in the number of breeding pairs in two skua species breeding on King George Island. Polar Biol 39:573-582

Lumpe P, Weidinger K (2000) Distribution, numbers and breeding of birds at the northern ice-free areas of Nelson Island, South Shetland Islands, Antarctica, 1990-1992. Mar Ornithol 28:41-46

Marchant S, Higgins PJ (1990) Handbook of Australia New Zealand and Antarctic birds Part A Ratites to Petrels, vol 1. Oxford University Press, Melbourne

Mougeot F, Genevois F, Bretagnolle V (1998) Predation on burrowing petrels by the Brown Skua (Catharacta skua lonnbergi) at Mayes Island, Kerguelen. J Zool 244:429-438

Pacoureau N, Gaget E, Delord K, Barbraud C (2019) Prey remains of brown skua is evidence of the long-term decline in burrow occupancy of blue petrels and thin-billed prions at Mayes Island, Kerguelen. Polar Biol 42:1873-1879

Peter H-U, Kaiser M, Gebauer A (1988) Untersuchungen an Vögeln und Robben auf King George Island (South Shetland Islands, Antarktis). Geodätische Und Geophysikalische Veröffentlichungen Reihe 1-14:1-127 
Peter H-U, Buesser C, Mustafa O, Pfeiffer S (2008) Risk assessment for the Fildes Peninsula and Ardley Island, and the development of management plans for their designation as Antarctic Specially Protected or Specially Managed Areas. On behalf of the German Environment Agency, Texte 20/2008, Dessau-Rosslau, http:// www.umweltbundesamt.de/publikationen/risk-assessment-forfildes-peninsula-ardley-island

Peter H-U, Braun C, Janowski S, Nordt A, Nordt A, Stelter M (2013) The current environmental situation and proposals for the management of the Fildes Peninsula Region. On behalf of the German Environment Agency, Texte 03/2013, Dessau-Rosslau, http:// www.umweltbundesamt.de/publikationen/current-environmentalsituation-proposals-for

Petry MV, Valls FCL, Petersen ES, Krüger L, Piuco RD, Dos Santos CR (2016) Breeding sites and population of seabirds on Admiralty Bay, King George Island, Antarctica. Polar Biol 39:1343-1349

Petry MV, Valls F, Petersen E, Finger JVG, Krüger L (2018) Population trends of seabirds at Stinker Point, Elephant Island, Maritime Antarctica. Antarct Sci 30:220-226

Reinhardt K, Hahn S, Peter H-U, Wemhoff H (2000) A review of the diets of Southern Hemisphere skuas. Mar Ornithol 28:7-19

Schrimpf M, Che-Castaldo C, Lynch HJ (2020) Regional breeding bird assessment of the Antarctic Peninsula. Polar Biol 43:111-122

Sierakowski K, Korczak-Abshire M, Jadwiszczak P (2017) Changes in bird communities of Admiralty Bay, King George Island (West Antarctic): insights from monitoring data (1977-1996). Pol Polar Res 38:231-262

Silva MP, Favero M, Casaux R, Baroni A (1998) The status of breeding birds at Harmony Point, Nelson Island, Antarctica in summer 1995/96. Mar Ornithol 26:75-78

Soave GE, Coria N, Silva P, Montalti D, Favero M (2000a) Diet of cape petrel Daption capense chicks on South Shetland Islands, Antarctica. Acta Ornithol 35:191-195

Soave GE, Coria NR, Montalti D, Curtosi A (2000b) Breeding flying birds in the region of the Fildes Peninsula, King George Island, South Shetland Islands, Antarctica, 1995/96. Mar Ornithol 28:37-40
Thibault M, Houlbreque F, Lorrain A, Vidal E (2019) Seabirds: Sentinels beyond the oceans. Science 366:813-813

Trathan PN, Forcada J, Murphy EJ (2007) Environmental forcing and Southern Ocean marine predator populations: effects of climate change and variability. Philos T R Soc B 362:2351-2365

Trathan PN, García-Borboroglu P, Boersma D et al (2015) Pollution, habitat loss, fishing, and climate change as critical threats to penguins. Conserv Biol 29:31-41

Turner J, Barrand NE, Bracegirdle TJ et al (2014) Antarctic climate change and the environment: an update. Polar Rec 50:237-259

Velarde E, Anderson DW, Ezcurra E (2019) Seabird clues to ecosystem health. Science 365:116-117

Weidinger K (1996a) Egg variability and hatching success in the Cape petrel Daption capense at Nelson Island, South Shetland Islands, Antarctica. J Zool 239:755-768

Weidinger K (1996b) Patterns of colony attendance in the Cape Petrel Daption capense at Nelson Island, South Shetland Islands, Antarctica. Ibis 138:243-249

Weidinger K (1997) Breeding cycle of the Cape petrel Daption capense at Nelson Island, Antarctica. Polar Biol 17:469-472

Weidinger K (1998a) Effect of predation by skuas on breeding success of the Cape petrel Daption capense at Nelson Island, Antarctica. Polar Biol 20:170-177

Weidinger K (1998b) Incubation and brooding rhythm of the Cape Petrel Daption capense at Nelson Island, South Shetland Islands, Antarctica. Ibis 140:163-170

Woehler EJ, Croxall JP (1997) The status and trends of Antarctic and sub-Antarctic seabirds. Mar Ornithol 25:43-66

Publisher's Note Springer Nature remains neutral with regard to jurisdictional claims in published maps and institutional affiliations. 